\title{
SARS-CoV-2 and Guillain-Barré syndrome: molecular mimicry with human heat shock proteins as potential pathogenic mechanism
}

\author{
Guglielmo Lucchese ${ }^{1}$ (D) - Agnes Flöel ${ }^{1,2}$
}

Received: 18 June 2020 / Revised: 16 July 2020 / Accepted: 23 July 2020 / Published online: 29 July 2020

(C) The Author(s) 2020

\begin{abstract}
Severe acute respiratory syndrome-related coronavirus 2 infection has been associated with Guillain-Barré syndrome. We investigated here the potential mechanism underlying the virus-induced damage of the peripheral nervous systems by searching the viral amino acid sequence for peptides common to human autoantigens associated with immune-mediated polyneuropathies. Our results show molecular mimicry between the virus and human heat shock proteins 90 and 60, which are associated with Guillain-Barré syndrome and other autoimmune diseases. Crucially, the shared peptides are embedded in immunoreactive epitopes that have been experimentally validated in the human host.
\end{abstract}

Keywords COVID-19 $\cdot$ Neuropathy $\cdot$ Demyelination

\section{Introduction}

The disease (COVID-19) caused by the severe acute respiratory syndrome-related coronavirus 2 (SARS-CoV-2) encompasses a broad array of symptoms and complications including most commonly fever, coughing, dyspnea, pneumonia, and respiratory failure, as well as less frequently myalgia, arthralgia, skin lesions, diarrhea, nausea, vomiting, and renal failure (Chen et al. 2020; Guan et al. 2020). Additionally, neurological involvement in the form of anosmia, ageusia, headache, nausea and vomiting, seizures, encephalopathy, and ischemic stroke has been described (Vaira et al. 2020; Asadi-Pooya and Simani 2020), possibly even as an indicator of unfavorable prognosis. In a retrospective study, it was found that $22 \%$ of the patients who died presented with disorders of consciousness at admission compared with $1 \%$ who recovered (Chen et al. 2020).

Electronic supplementary material The online version of this article (https://doi.org/10.1007/s12192-020-01145-6) contains supplementary material, which is available to authorized users.

Guglielmo Lucchese

guglielmo.lucchese@uni-greifswald.de

1 Department of Neurology, Universitätsmedizin Greifswald, Ferdinand-Sauerbruch-Str, 17475 Greifswald, Germany

2 German Center for Neurodegenerative Diseases, Rostock/ Greifswald, Greifswald, Germany
However, the exact pathogenesis of COVID-19-related neurological damage is still largely unknown, and diverse mechanisms might play a role. Neurotropism of coronaviruses is well known, and SARS-CoV-2 and SARS-CoV, among others, are not confined to the respiratory tract but can also invade the central nervous system ( $\mathrm{Li}$ et al. 2020). At the same time, evidence is mounting that COVID-19 is associated with immunemediated neurological complications, for example, in the form of Guillain-Barré syndrome (GBS) (Toscano et al. 2020; Coen et al. 2020). Indeed, neurological sequelae of infections are a well described phenomenon, and previous viral epidemic outbreaks have already shown that immune-mediated mechanisms may induce damage to the nervous system and specifically GBS (Cao-Lormeau et al. 2016; Lucchese and Kanduc 2016), which is a classical example of molecular mimicry (Dalakas et al. 2015). Among other mechanisms, molecular mimicry between SARS-CoV-2 and various human organs and tissues has been already postulated as possible trigger of multi-organ autoimmunity in COVID-19 (Cappello 2020; Angileri et al. 2020a, b).

We tested here the hypothesis that neuropathy in COVID-19 might be the consequence of molecular mimicry between the SARS-CoV-2 and human autoantigens involved in inflammatory polyneuropathies by analyzing the peptide sharing between the virus and such protein antigens. 


\section{Materials and methods}

A set formed by the primary amino acid (aa) sequences of 41 human protein antigens associated with acute (GBS; Miller Fisher Syndrome) and chronic (chronic inflammatory demyelinating polyneuropathy, CIDP; multifocal motor neuropathy, MMN) immune-mediated neuropathies was retrieved from the UniProt database (Table 1; www.uniprot.org, Magrane et al. 2011).

The entire primary aa sequence of the SARS-CoV-2 was retrieved from https://www.ncbi.nlm.nih.gov/nuccore/ MN908947 and dissected into hexapeptides overlapping by 5 residues (for instance, MESLVP, ESLVPG, SLVPGF, and so forth) for a total of $n=9649$.

Then, each viral peptide was analyzed for occurrences in the set of neuropathy-related protein antigens obtained as described above. The SARS-CoV-2 hexamers were analyzed for occurrences in a set of human dentin-related proteins as negative control (chosen as instance of human tissue not affected by COVID-19). The set was retrieved by searching for "dentin" in the UniProt database and consists of 86 proteins that are listed in the Supplementary Table S1. The analyses were carried out with custom scripts for the MATLAB programming environment.

The Immune Epitope Database (IEDB; www.iedb.org) resource was used to explore the immunological relevance of the shared motifs (Vita et al. 2015). The IEDB was searched for linear epitopes with reported positive $\mathrm{T}$ and/or B cell assays in the human host and containing the hexapeptides shared by SARS-CoV-2 and the GBS-related protein antigens. The IEDB is a curated immunological repository containing epitopes that have been experimentally validated as immunopositive.
Table 1 Protein antigens associated with acute and chronic immune-mediated neuropathies (UniProt-ID, Acronym, Name, Gene)
O94856-8 NFASC Isoform 8 (NF155) of Neurofascin GN=NFASC (Querol et al. 2017; Burnor et al. 2018) O94856-4 NFASC Isoform 4 (NF140) of Neurofascin GN=NFASC (Burnor et al. 2018) O94856-1 NFASC Neurofascin (NF186) GN=NFASC (Burnor et al. 2018)

P05455 LA Lupus La protein GN=SSB (Querol et al. 2017) P07900 HS90A Heat shock protein HSP 90-alpha GN=HSP90AA1 (Yonekura et al. 2004) P08238 HS90B Heat shock protein HSP 90-beta GN=HSP90AB1 (Yonekura et al. 2004) P0DMV8 HS71A Heat shock $70 \mathrm{kDa}$ protein 1A GN=HSPA1A (Yonekura et al. 2004) P10155 RO60 60 kDa SS-A/Ro ribonucleoprotein GN=RO60 (Yonekura et al. 2004) P10809 CH60 60 kDa Heat shock protein, mitochondrial GN=HSPD1 (Yonekura et al. 2004) P11142 HSP7C Heat shock cognate $71 \mathrm{kDa}$ protein GN=HSPA8 (Yonekura et al. 2004) P14625 ENPL Endoplasmin GN=HSP90B1 (Yonekura et al. 2004) P17066 HSP76 Heat shock 70 kDa protein 6 GN=HSPA6 (Yonekura et al. 2004) P20916 MAG Myelin-associated glycoprotein GN=MAG (Querol et al. 2017) P22607 FGFR3 Fibroblast growth factor receptor 3 GN=FGFR3 (Querol et al. 2017) P26038 MOES Moesin GN=MSN (Sawai et al. 2014) P26378 ELAV4 ELAV-like protein 4 GN=ELAVL4 (Querol et al. 2017) P34931 HS71L Heat shock $70 \mathrm{kDa}$ protein 1-like GN=HSPA1L (Yonekura et al. 2004) P34932 HSP74 Heat shock $70 \mathrm{kDa}$ protein 4 GN=HSPA4 (Yonekura et al. 2004) P38646 GRP75 Stress-70 protein, mitochondrial GN=HSPA9 (Yonekura et al. 2004) P48741 HSP77 Putative heat shock $70 \mathrm{kDa}$ protein 7 GN=HSPA7 (Yonekura et al. 2004) P54652 HSP72 Heat shock-related $70 \mathrm{kDa}$ protein $2 \mathrm{GN}=\mathrm{HSPA} 2$ (Yonekura et al. 2004) P61604 CH10 10 kDa Heat shock protein, mitochondrial GN=HSPE1 (Yonekura et al. 2004) P78357 CNTP1 Contactin-associated protein $1 \mathrm{GN}=\mathrm{CNTNAP1}$ (Querol et al. 2017) Q0VDF9 HSP7E Heat shock $70 \mathrm{kDa}$ protein $14 \mathrm{GN}=\mathrm{HSPA} 14$ (Yonekura et al. 2004) Q12860 CNTN1 Contactin-1 GN=CNTN1 (Querol et al. 2017) Q12926 ELAV2 ELAV-like protein 2 GN=ELAVL2 (Querol et al. 2017) Q12988 HSPB3 Heat shock protein beta-3 GN=HSPB3 (Yonekura et al. 2004) Q14576 ELAV3 ELAV-like protein 3 GN=ELAVL3 (Querol et al. 2017) Q15717 ELAV1 ELAV-like protein 1 GN=ELAVL1 (Querol et al. 2017) Q16543 CDC37 Hsp90 co-chaperone Cdc37 GN=CDC37 (Yonekura et al. 2004) Q58FF3 ENPLL Putative endoplasmin-like protein GN=HSP90B2P (Yonekura et al. 2004) Q58FF6 H90B4 Putative heat shock protein HSP 90-beta 4 GN=HSP90AB4P (Yonekura et al. 2004) Q58FF7 H90B3 Putative heat shock protein HSP 90-beta-3 GN=HSP90AB3P (Yonekura et al. 2004) Q58FF8 H90B2 Putative heat shock protein HSP 90-beta 2 GN=HSP90AB2P (Yonekura et al. 2004) Q58FG0 HS905 Putative heat shock protein HSP 90-alpha A5 GN=HSP90AA5P (Yonekura et al. 2004) Q58FG1 HS904 Putative heat shock protein HSP 90-alpha A4 GN=HSP90AA4P (Yonekura et al. 2004) Q6ZMI3 GLDN Gliomedin GN=GLDN (Querol et al. 2017) Q7L3B6 CD37L Hsp90 co-chaperone Cdc37-like 1 GN=CDC37L1 (Yonekura et al. 2004) DPYL5 Dihydropyrimidinase-related protein 5 GN=DPYSL5 (Querol et al. 2017) HPBP1 Hsp70-binding protein $1 \mathrm{GN}=\mathrm{HSPBP} 1$ (Yonekura et al. 2004) CNTP2 Contactin-associated protein-like 2 GN=CNTNAP2 (Querol et al. 2017) 


\section{Results}

Sequence analysis of the 41 human proteins associated with acute and chronic immune-mediated neuropathies (Table 1) showed that SARS-CoV-2 shares two immunologically relevant hexapeptides (KDKKKK and EIPKEE) with the human heat shock proteins 90 (HSP90B and HSP90B2) and 60 (HSP60), respectively (Table 2). The former hexapeptide is part of 5 experimentally validated epitopes from the SARS$\mathrm{CoV}$, as catalogued in the IEDB; the latter is part of 1 experimentally validated autoimmune epitope recognized by lymphomononuclear cells of multiple sclerosis (MS) patients (Ruiz-Vázquez and de Castro 2003).

No sharing of immunologically relevant hexapeptides was found between SARS-CoV-2 and the human dentin-related proteins. More details can be found in the supplementary material.

\section{Discussion}

We show in the present study that the SARS-CoV-2 shares aa sequences of proven immunologic potential with the human heat shock proteins (HSPs). HSPs have also been involved in a number of immune-mediated clinical conditions, and they can become the target of immune response, possibly as a consequence of molecular mimicry (Moudgil et al. 2013).

Important from a neurological perspective, autoantibodies targeting different families of HSPs have been shown to be elevated in serum and cerebrospinal fluid (CSF) of patients affected by myasthenia gravis, MS, and, crucially, GBS (Romi et al. 2011). The sharing of peptide motifs with immunologic potential, as demonstrated by their presence within human experimentally validated epitopes, between the virus and HSPs, therefore strongly supports an immune-mediated neurological damage in COVID-19.

In particular, the hexapeptide shared with the HSP90B and HSP90B2 is part of 5 experimentally validated epitopes from the SARS-CoV, as catalogued in the IEDB. Crucially, the hexapeptide is located proximally (epitope-ID: 30186) in the middle (epitope-ID: 13680 ; 63494) and terminally (epitopeID: $33669 ; 74517$ ) in these epitopes (see Table 2), thus constituting the only aa sequence common to all of the epitopes. It is therefore highly likely that the shared hexapeptide is the immunogenic determinant of all the five epitopes. This hexapeptide thus constitutes the ideal candidate to elicit an autoimmune response against HS90B and H90B2 as a consequence of SARS-CoV2 infection.

The second immunologically relevant motif shared by the SARS-CoV-2 and human HSPs belongs to the chaperone protein 60 and, interestingly, has been shown to be recognized by lympho-monocytes of patients affected by demyelinating disease of the central nervous systems (CNS; Ruiz-Vázquez and de Castro 2003). This finding warrants further investigation of a possible association of SARS-CoV-2 infection with inflammation and demyelination not only in the PNS but also in the CNS, which appears to be supported by preliminary clinical reports (Zanin et al. 2020).

HSP60 is a mitochondrial protein that is normally not exposed on the plasma membrane. Nevertheless, immune reactions against intracellular autoantigens are a well-known phenomenon (Greenlee et al. 2015; Racanelli et al. 2011). Moreover, Cappello et al. (2020) postulated that posttranslational modifications (PTMs) to HSPs could induce protein translocation to plasma membrane, and indeed HSP60 localization to the plasma membrane after PTMs has been described

Table 2 Hexapeptides of immunologic relevance shared between SARS-CoV-2 and GBS-related proteins as catalogued in the Immune Epitope Database (IEDB; www.iedb.org) 12

\begin{tabular}{|c|c|c|c|}
\hline $\begin{array}{l}\text { Shared } \\
\text { 6-mer }\end{array}$ & $\begin{array}{l}\text { SARS-CoV-2 } \\
\text { protein }\end{array}$ & $\begin{array}{l}\text { Human proteins } \\
\text { [UniProt-ID; Gene] }\end{array}$ & $\begin{array}{l}\text { Epitopes } \\
\text { [IEDB-ID; Protein; Organism] }\end{array}$ \\
\hline KDKKKK & $\begin{array}{l}\text { Nucleocapsid } \\
\text { Phosphoprotein }\end{array}$ & $\begin{array}{l}\text { Heat shock protein 90-beta } \\
\text { [P08238; HSP90AB1] } \\
\text { Putative heat shock protein } \\
\text { 90-beta 2 } \\
\text { [Q58FF8; HSP90AB2P] }\end{array}$ & $\begin{array}{l}\text { KDKKKKTDEAQPLPQRQKKQ } \\
\text { [30186; Nucleoprotein; SARS-CoV] } \\
\text { EPKKDKKKKTDEAQPL } \\
\text { [13680; Nucleoprotein; SARS-CoV] } \\
\text { KTFPPTEPKKDKKKK } \\
\text { [33669; Nucleoprotein; SARS-CoV] } \\
\text { TEPKKDKKKKTDEAQPLPQRQKK + ACET(T1) } \\
\text { [63494; Nucleoprotein; SARS-CoV] } \\
\text { YKTFPPTEPKKDKKKK } \\
\text { [74517; Nucleoprotein; SARS-CoV] }\end{array}$ \\
\hline EIPKEE & $\begin{array}{l}\text { Orflab } \\
\text { Polyprotein }\end{array}$ & $\begin{array}{l}60 \mathrm{kDa} \text { heat shock protein, } \\
\text { mitochondrial } \\
\text { [P10809; HSPD1] }\end{array}$ & $\begin{array}{l}\text { VVTEIPKEEKDPGM } \\
{[112717 ; 60 \mathrm{kDa} \text { heat shock protein; Homo sapiens }]}\end{array}$ \\
\hline
\end{tabular}

Each row presents one shared hexamer (first column), the SARS-CoV-2 protein (second column), the human GBS-related protein(s) (third column), and the experimentally validated immunogenic epitopes containing the same hexamer (last column) 
(Caruso Bavisotto et al. 2020). Multiple concurrent mechanisms could then explain immune reactions against HSP60 in case of autoimmunity.

In sum, the present data point to immunological targeting of the HSPs 90B, 90B2, and 60 as a potential pathogenic mechanism of neuropathy after SARS-CoV-2 infection and suggest to specifically test sera and CSF of COVID-19 patient affected by GBS and possibly other peripheral neuropathies for autoantibodies against these proteins. Moreover, this data add up to previous literature (Lucchese \& Flöel 2020, Lucchese 2020, Cappello et al. 2020) bearing relevance for potential immunomodulatory therapy as well as passive and active immunization in COVID-19.

Acknowledgements Open Access funding provided by Projekt DEAL.

Author contribution The authors contributed equally to this work.

Funding information The authors acknowledge a "Gerhard Domagk" research grant awarded to GL by the University of Greifswald and a research grant awarded to AF by the Deutsche Forschungsgemeinschaft (DFG, German Research Foundation) - Project number 327654276 SFB 1315 .

\section{Compliance with ethical standards}

Conflict of interest GL reports grant support from the University of Greifswald. AF reports grant support from the German Research Foundation, German Federal Ministry of Education and Research, European Union, Else Kröner Fresenius Stiftung, and Hannelore Kohl Stiftung; consultant fees from Novartis and Bayer; and honorariums for presentations in scientific symposia by Novartis and Bayer, all outside the submitted work. GL and AF are listed as inventors on a patent application for a SARS-CoV-2 vaccine.

Open Access This article is licensed under a Creative Commons Attribution 4.0 International License, which permits use, sharing, adaptation, distribution and reproduction in any medium or format, as long as you give appropriate credit to the original author(s) and the source, provide a link to the Creative Commons licence, and indicate if changes were made. The images or other third party material in this article are included in the article's Creative Commons licence, unless indicated otherwise in a credit line to the material. If material is not included in the article's Creative Commons licence and your intended use is not permitted by statutory regulation or exceeds the permitted use, you will need to obtain permission directly from the copyright holder. To view a copy of this licence, visit http://creativecommons.org/licenses/by/4.0/.

\section{References}

Angileri F, Légaré S, Marino Gammazza A, Conway de Macario E, Jl Macario A, Cappello F (2020a) Molecular mimicry may explain multi-organ damage in COVID-19. Autoimmun Rev 102591. https://doi.org/10.1016/j.autrev.2020a.102591

Angileri F, Légaré S, Marino Gammazza A, Conway de Macario E, AJL $\mathrm{M}$, Cappello F (2020b, in press) Is molecular mimicry the culprit in the autoimmune haemolytic anaemia affecting patients with COVID-19? Br J Haematol. https://doi.org/10.1111/bjh.16883
Asadi-Pooya AA, Simani L (2020) Central nervous system manifestations of COVID-19: a systematic review. J Neurol Sci 413:116832. https://doi.org/10.1016/j.jns.2020.116832

Burnor E, Yang L, Zhou H, Patterson KR, Quinn C, Reilly MM, Rossor AM, Scherer SS, Lancaster E (2018) Neurofascin antibodies in autoimmune, genetic, and idiopathic neuropathies. Neurology. 90: e31-e38. https://doi.org/10.1212/WNL.0000000000004773

Cao-Lormeau VM, Blake A, Mons S, Lastère S, Roche C, Vanhomwegen J, Dub T, Baudouin L, Teissier A, Larre P, Vial AL, Decam C, Choumet V, Halstead SK, Willison HJ, Musset L, Manuguerra JC, Despres P, Fournier E, Mallet HP, Musso D, Fontanet A, Neil J, Ghawché F (2016) Guillain-Barré syndrome outbreak associated with Zika virus infection in French Polynesia: a case-control study. Lancet. 387:1531-1539. https://doi.org/10. 1016/S0140-6736(16)00562-6

Cappello F (2020) Is COVID-19 a proteiform disease inducing also molecular mimicry phenomena? Cell Stress Chaperones 25:381-382. https://doi.org/10.1007/s12192-020-01112-1

Cappello F, Gammazza AM, Dieli F, de Macario MAJ (2020) Does SARS-CoV-2 trigger stress-induced autoimmunity by molecular mimicry? A Hypothesis. J Clin Med 9:E2038. https://doi.org/10. 3390/jcm9072038

Caruso Bavisotto C, Alberti G, Vitale AM, Paladino L, Campanella C, Rappa F, Gorska M, Conway de Macario E, Cappello F, Macario AJL, Marino Gammazza A (2020) Hsp60 post-translational modifications: functional and pathological consequences. Front Mol Biosci 7:95. https://doi.org/10.3389/fmolb.2020.00095

Chen T, Wu D, Chen $\mathrm{H}$ et al (2020) Clinical characteristics of 113 deceased patients with coronavirus disease 2019: retrospective study. BMJ:368

Coen M, Jeanson G, Alejandro Culebras Almeida L et al (2020) GuillainBarré syndrome as a complication of SARS-CoV-2 infection [published online ahead of print, 2020 Apr 28]. Brain Behav Immun S0889 1591(20):30698-X. https://doi.org/10.1016/j.bbi.2020.04.074

Dalakas MC (2015) Pathogenesis of immune-mediated neuropathies. Biochim Biophys Acta 1852:658-666. https://doi.org/10.1016/j. bbadis.2014.06.013

Greenlee JE, Clawson SA, Hill KE, Wood B, Clardy SL, Tsunoda I, Carlson NG (2015) Anti-Yo antibody uptake and interaction with its intracellular target antigen causes Purkinje cell death in rat cerebellar slice cultures: a possible mechanism for paraneoplastic cerebellar degeneration in humans with gynecological or breast cancers. PLoS One 10:e0123446. https://doi.org/10.1371/journal.pone. 0123446

Guan WJ, Ni ZY, Hu Y, Liang WH, Ou CQ, He JX, Liu L, Shan H, Lei CL, Hui DSC, du B, Li LJ, Zeng G, Yuen KY, Chen RC, Tang CL, Wang T, Chen PY, Xiang J, Li SY, Wang JL, Liang ZJ, Peng YX, Wei L, Liu Y, Hu YH, Peng P, Wang JM, Liu JY, Chen Z, Li G, Zheng ZJ, Qiu SQ, Luo J, Ye CJ, Zhu SY, Zhong NS, China Medical Treatment Expert Group for Covid-19 (2020) Clinical characteristics of coronavirus disease 2019 in China. N Engl J Med 382: 1708-1720. https://doi.org/10.1056/NEJMoa2002032

Li YC, Bai WZ, Hashikawa T (2020) The neuroinvasive potential of SARS$\mathrm{CoV} 2$ may play a role in the respiratory failure of COVID-19 patients. J Med Virol 92:552-555. https://doi.org/10.1002/jmv.25728

Lucchese G (2020) Epitopes for a 2019-nCoV vaccine. Cell Mol Immunol 17:539-540. https://doi.org/10.1038/s41423-020-0377-z

Lucchese G, Kanduc D (2016) Zika virus and autoimmunity: from microcephaly to Guillain-Barré syndrome, and beyond. Autoimmun Rev 15:801-808. https://doi.org/10.1016/j.autrev.2016.03.020

Lucchese G, Flöel A (2020) Molecular mimicry between SARS-CoV-2 and respiratory pacemaker neurons. Autoimmun Rev 19:102556. https://doi.org/10.1016/j.autrev.2020.102556

Magrane M, UniProt Consortium, UniProt Knowledgebase (2011) A hub of integrated protein data. Database 2011:bar009 
Moudgil KD, Thompson SJ, Geraci F, De Paepe B, Shoenfeld Y (2013) Heat-shock proteins in autoimmunity. Autoimmune Dis 2013: 621417-621413. https://doi.org/10.1155/2013/621417

Querol L, Devaux J, Rojas-Garcia R, Illa I (2017) Autoantibodies in chronic inflammatory neuropathies: diagnostic and therapeutic implications. Nat Rev Neurol 13:533-547. https://doi.org/10.1038/ nrneurol.2017.84

Racanelli V, Prete M, Musaraj G, Dammacco F, Perosa F (2011) Autoantibodies to intracellular antigens: generation and pathogenetic role. Autoimmun Rev 10:503-508. https://doi.org/10.1016/j. autrev.2011.03.001

Romi F, Helgeland G, Gilhus NE (2011) Heat-shock proteins in clinical neurology. Eur Neurol 66:65-69. https://doi.org/10.1159/ 000329373

Ruiz-Vázquez E, de Castro P (2003) "2-6-11" motif in heat shock protein 60 and central nervous system antigens: a preliminary study in multiple sclerosis patients. J Physiol Biochem 59:1-9. https://doi.org/ 10.1007/BF03179862

Sawai S, Satoh M, Mori M, Misawa S, Sogawa K, Kazami T, Ishibashi M, Beppu M, Shibuya K, Ishige T, Sekiguchi Y, Noda K, Sato K, Matsushita K, Kodera Y, Nomura F, Kuwabara S (2014) Moesin is a possible target molecule for cytomegalovirus-related Guillain-Barré syndrome. Neurology. 83:113-117. https://doi.org/10.1212/WNL. 0000000000000566
Toscano G, Palmerini F, Ravaglia S, Ruiz L, Invernizzi P, Cuzzoni MG, Franciotta D, Baldanti F, Daturi R, Postorino P, Cavallini A, Micieli G (2020) Guillain-Barré syndrome associated with SARS-CoV-2. N Engl J Med 382:2574-2576. https://doi.org/10.1056/ NEJMc2009191

Vaira LA, Salzano G, Deiana G, De Riu G (2020) Anosmia and Ageusia: common findings in COVID-19 patients. Laryngoscope. 130:1787. https://doi.org/10.1002/lary.28692

Vita R, Overton JA, Greenbaum JA, Ponomarenko J, Clark JD, Cantrell JR, Wheeler DK, Gabbard JL, Hix D, Sette A, Peters B (2015) The immune epitope database (IEDB) 3.0. Nucleic Acids Res 43:D405D412. https://doi.org/10.1093/nar/gku938

Yonekura K, Yokota S, Tanaka S, Kubota H, Fujii N, Matsumoto H, Chiba S (2004) Prevalence of anti-heat shock protein antibodies in cerebrospinal fluids of patients with Guillain-Barré syndrome. J Neuroimmunol 156:204-209. https://doi.org/10.1016/j.jneuroim. 2004.07.017

Zanin L, Saraceno G, Panciani PP et al (2020) SARS-CoV-2 can induce brain and spine demyelinating lesions. Acta Neurochir:1-4. https:// doi.org/10.1007/s00701-020-04374-x

Publisher's note Springer Nature remains neutral with regard to jurisdictional claims in published maps and institutional affiliations. 